\title{
DE OPERADOR A INTEGRADOR LOGÍSTICO: UM ESTUDO DE CASO NA INDÚSTRIA DE SAÚDE ANIMAL
}

\section{FROM THIRD-PARTY TO FOURTH-PARTY LOGISTICS: A CASE STUDY IN THE ANIMAL HEALTH INDUSTRY}

\author{
Wilian Gatti Junior ${ }^{1}$ \\ ${ }^{1}$ Universidade de São Paulo - USP - São Paulo - Brasil \\ wgatti@usp.br
}

\begin{abstract}
Resumo
A complexidade gerencial resultante do fluxo de materiais e informações entre redes de empresas fez surgir a idéia de um agente integrador de processos atuando nessas redes. Para este novo papel especula-se que esses novos agentes devam incorporar atividades na cadeia de suprimentos à medida que elevam o nivel de relacionamento com a empresa contratante. Esta pesquisa tem por objetivo apresentar oportunidades de atuação para um operador logístico, altamente integrado com seu cliente nos moldes descritos como a "organização em rede" e diferenciá-lo dos demais agentes que operam na indústria de terceirização de operações logísticas. Nesse estágio o operador logístico estaria caracterizado como um integrador logístico. A pesquisa cruzou evidências empíricas coletas em um estudo de caso com oito processos identificados na literatura para a gestão da cadeia de suprimentos. A construção do estudo de caso compreendeu a observação participante, entrevistas com funcionários e ex-funcionários das empresas envolvidas e dados coletados de fontes secundárias. Identificou-se que o operador logístico poderia se diferenciar dos demais prestadores de serviços logísticos, por meio da oferta de soluções integradas e específicas para o segmento de negócio de seu cliente desenvolvendo múltiplos processos ao longo da cadeia de suprimentos. Para isto, deve possuir elevada capacidade de planejamento estratégico e operacional apoiado com grande infra-estrutura tecnológica.
\end{abstract}

Palavras-chave: operador logístico; integrador logístico; cadeia de suprimentos.

\section{Introdução}

Com o aumento da interação global de negócios, o fluxo de materiais e informações entre redes de empresas tornou ainda mais complexa as atividades relacionadas à implantação, operacionalização e controle de operações logísticas. Essa responsabilidade requer a aplicação de conhecimento técnico específico e habilidades gerenciais para a coordenação e integração de processos além das fronteiras da organização. Na visão de Lima (2004b) a preocupação empresarial com relação às operações logísticas é motivada pela crescente exigência dos clientes, a adoção em grande escala dos movimentos de qualidade, a estabilidade da moeda (para a realidade brasileira), a 
crescente utilização de alianças e parcerias estratégicas e a revolução da informação - onde os dados trafegam em velocidade superior a dos materiais.

A incapacidade das organizações em lidar com a complexidade desse ambiente motivou o surgimento de uma indústria emergente, voltada à terceirização de processos logísticos com a promessa de otimizar de modo integrado os recursos empresariais voltados ao suprimento, produção e distribuição de produtos. As parcerias logísticas formadas a partir da terceirização possibilitaram a criação de benefícios mútuos para todos os participantes envolvidos (LIMA, 2004a). Com o corpo gerencial pressionado a agregar valor aos produtos e serviços da empresa em todas as fases de seu fluxo, incluindo armazenagem e expedição, observou-se ao longo dos anos uma crescente busca por parceiros de negócio especialistas nessas operações. Frente às pressões exercidas sobre a logística, a terceirização tem como propósito básico aumentar a eficiência e a eficácia das práticas de negócio na cadeia de suprimentos, via criação de vantagem competitiva sustentável a longo prazo (WANKE; FLEURY, 2001, apud LIMA, 2004a).

O aprofundamento das relações de redes de empresas promoveu uma alteração no entendimento do conceito de logística para uma idéia mais abrangente: o gerenciamento da cadeia de suprimentos ou supply chain management (SCM) (COOPER; LAMBERT; PAGH, 1997). Na esteira dessa evolução na indústria dos prestadores de serviços logísticos (PSL), a discussão do conceito de operador logístico ou 3PL (third-party logistics) se aprofundou com a introdução do conceito de integrador logístico ou 4PL (fourth-party logistics), termo criado pela empresa de consultoria Accenture, antiga Andersen Consulting (CHRISTOPHER, 2007; LIMA, 2004a; YAO, 2008). Vivaldini, Pires e Souza (2008) destacam em seu modelo teórico que o PSL ao incorporar atividades e serviços diversos tem a oportunidade de atuar como integrador na cadeia de suprimentos. Selviaridis e Spring (2007) ressaltam, porém a necessidade de novos estudos para o entendimento claro sobre o escopo de trabalho destes integradores, o que também é destacado por Yao (2008) que alega não haver muitas pesquisas que se dedicaram a conceituar este novo prestador de serviços logísticos. Deste modo, seu formato e definições ainda continuam controversos.

Realizando o cruzamento das evidências empíricas coletas em um estudo de caso com os oito macro-processos do SCM estabelecidos por Croxton et al. (2001) e Lambert, Cooper e Pagh (1998), esta pesquisa tem por objetivo apresentar oportunidades de diferenciação para um 3PL altamente integrado com seu cliente, nos moldes descritos por Franceschini et al. (2003) como a "organização em rede" onde se especula que o 3PL passaria a atuar no nível que foi conceituado como 4PL. Essa caracterização permite diferenciá-lo dos demais agentes que operam na indústria de terceirização de operações logísticas, com base na categorização apresentada por Razzaque e Sheng (1999).

O trabalho justifica-se pela possibilidade de contribuir com o debate (tanto acadêmico como 
gerencial) sobre essa nova e emergente classe de PSL ainda sem um escopo de atuação definido. A pesquisa também pode ser útil para o entendimento da gestão da cadeia de suprimentos, pois há um claro descompasso entre teoria e prática e como integrá-la (FAWCETT; MAGNAN, 2002).

\section{A terceirização}

Franceschini et al. (2003) propõem o entendimento da mudança do conceito de terceirização de uma posição tradicional para uma estratégica. De uma atividade que exigia habilidades específicas do fornecedor em processos não essenciais para a empresa (ex.: serviços de limpeza e alimentação), a terceirização se propõe a abranger várias atividades, exceto aquelas que geram vantagem competitiva. Franceschini et al. (2003) definem quatro tipos de relacionamentos entre contratante e fornecedor descritos na figura 1.

Figura 1: Tipos de relacionamentos contratante $\mathrm{x}$ fornecedor

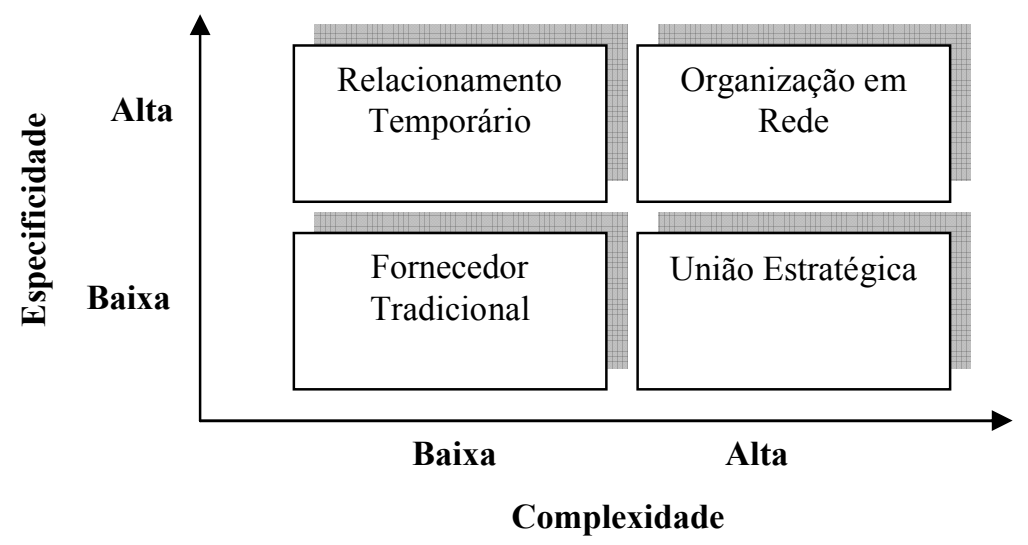

Fonte: Franceschini et al., 2003

A especificidade diz respeito ao nível de reutilização dos processos/produtos em diversas aplicações, desde modo quanto maior a especificidade, maior a capacidade de operar de modo particular. Em geral está atrelada a localização geográfica ou a habilidades exclusivas em termos de recursos e técnicas. Por sua vez, a complexidade refere-se à dificuldade no planejamento, execução e controle dos processos envolvidos no contrato de terceirização.

O fornecedor tradicional é contratado para a resolução de problemas imediatos e é avaliado por sua produtividade, redução de custos e tempo de reação. O relacionamento temporário permite a empresa contratante obter melhores habilidades, onde o fornecedor é avaliado por sua condição em oferecer maior eficiência aos processos terceirizados. No conceito de união estratégica, as relações se caracterizam por parcerias de longo prazo e a operação do fornecedor é conduzida pela estratégia de seus clientes. O objetivo desta relação é a agregação de valor. O mais elevado grau de terceirização, definido por Franceschini et al. (2003) como organização em rede, caracteriza-se por parcerias de longo prazo, onde o fornecedor é contratado por sua capacidade de inovação e criação 
de novos mercados. Nesse estágio o objetivo da terceirização é, em uma visão de futuro, melhorar o posicionamento da empresa no mercado.

A terceirização logística pode ser expressa pelas definições de Franceschini et al. (2003). Nos processos logísticos, em geral, as transportadoras contratadas para entregas pontuais se enquadram neste tipo de relacionamento definido como fornecedor tradicional. Contratos com PSLs que visam prioritariamente à redução de custos atrelados a contratos de médio prazo, como operações de movimentação e armazenagem, são exemplos de relacionamento temporário. Muitos contratos de terceirização logística com a utilização de $3 \mathrm{PL}$ se enquadram no conceito de união estratégica. Neste sentido, o 3PL é medido por sua capacidade de proporcionar vantagens competitivas e lucro aos seus clientes. Para Lima (2004b) as empresas contratam os serviços dos 3PL com uma expectativa sobre a redução dos custos, a qualidade do serviço, o aumento da rentabilidade do negócio e o crescimento de market share. Na organização em rede, este estudo sugere que o relacionamento de um 3PL evoluiria para o conceito de 4PL. A demanda por operações mais sofisticadas e o foco na gestão da informação e na coordenação de operações, com o emprego de recursos específicos no mercado de atuação da empresa contratante, resultariam no surgimento do novo conceito.

\section{Operadores Logísticos - third-party logistics (3PL)}

Para Fleury e Ribeiro (2001b) são diversas as possibilidades de terceirização logística, passando de soluções específicas para problemas de armazenagem ou transporte, até a contratação de terceiros para operar todo o processo logístico. Para Lieb (1996, apud FLEURY 1999), a denominação 3PL se aplica tanto às empresas que prestam todos os serviços ligados ao processo logístico, quanto àquelas de fornecem apenas uma atividade específica deste processo. Sink (1997) acredita que as funções logísticas terceirizadas devem ser coordenadas de modo integrado, assim como Berglund (1999) que defende que um 3PL deve oferecer, no mínimo, dois tipos de serviços integrados. Acrescentam ainda que "várias destas empresas fizeram alianças para ampliar sua capacidade de comercializar todo o serviço logístico demandado de um único cliente".

Para Dornier et al. (2000) a combinação entre serviços físicos (armazém, transporte) e gerenciais é o modelo sobre o qual recaem os serviços fornecidos pelas empresas de serviços logísticos e logística terceirizada (3PL). Do mesmo modo que Novaes (2001) define operador logístico integrado como a organização que fornece simultaneamente serviços administrativos e físico-operacionais, por meio da combinação da utilização de ativos e sistemas de informações e comunicações conforme as necessidades dos clientes e de forma a permitir uma maior eficiência da cadeia de suprimentos. Murphy e Poist (2000) além de incluir em sua definição uma abrangente oferta de serviços personalizados oferecidos, incluem também na caracterização de um 3PL, a 
construção de relacionamentos de longo prazo e mutuamente benéficos.

A indústria de operadores logísticos originou-se basicamente dos prestadores de serviços logísticos que de algum modo, proviam parte das soluções logísticas para seus clientes. Desta forma, encontram-se operadores com origens em empresas de transporte e distribuição (ex.: Marbo, TA Log, Cometa), incluindo empresas de courier como UPS, Fedex e TNT e empresas de armazenagem (ex.: Columbia). Além destes, empresas industriais também contribuíram para a constituição de operadores logísticos (ex.: DDF da Philips).

\section{A indústria de operadores logísticos no Brasil}

Fleury e Aline (2001a) destacam que o mercado de operadores logísticos apresentou enorme evolução nos últimos anos. Mesmo sendo uma indústria bastante jovem, o mercado brasileiro se equivale aos padrões apresentados nos mercados norte-americanos, europeu e asiático ao contar com sua base de operadores formados por empresas nacionais e grandes grupos estrangeiros, originários de prestadores de serviços de transporte, armazenagem e entrega expressa, sendo estas atividades ainda as que mais contribuem para seu faturamento. Fleury e Aline (2001a) também destacam a expressiva concentração dos operadores logísticos na região Sudeste do país.

Como em outros mercados (EUA, Europa e Ásia), as dificuldades vivenciadas pela indústria de operadores no Brasil estão relacionadas à capacitação da mão de obra e a pressão exercida pelos clientes para a redução de preços e pela manutenção de um alto desempenho operacional. Com base em uma série de reportagens sobre o mercado brasileiro de operadores logísticos, da revista Tecnologística $(2001,2002,2003,2004,2005)$, foi possível reconstituir um pouco da história recente desta indústria no país.

O primeiro operador logístico estabeleceu-se no Brasil em 1986, a Brasildocks, para atender a Pirelli, mas o grande marco do setor foi a DDF oriunda do departamento de distribuição física da Philips e que hoje, após se adquirida pela Danzas, foi adquirida pela DHL.

Das origens da indústria de operadores no Brasil aos dias de hoje, observou-se que após a avalanche do comércio eletrônico, o crescimento dos operadores logísticos se estabilizou e começou a apresentar uma tendência de crescimento moderado, porém ordenado e contínuo. O país começou a experimentar mais fortemente a partir de 2001, a entrada de empresas internacionais, em grande medida, por meio de associação com empresas nacionais. É dessa mesma época, a percepção alcançada pelo emergente mercado de operadores logísticos que o fluxo de informações seria uma das principais necessidades para a sobrevivência e triunfo sobre a concorrência. Os primeiros e grandes investimentos em tecnologia de informação se fizeram notar.

A partir do ano seguinte, em 2002, os operadores apontaram o início da consolidação do conceito de SCM, reflexo da oferta de soluções completas executadas por um único operador como 
montagens de kits e personalização de embalagens. A atratividade sugerida pela nova forma de operar processos logísticos de forma integrada liderou o início da migração das transportadoras para o negócio de operações logísticas. As indústrias acompanharam este processo e buscaram operadores logísticos capazes de levar suas operações a um novo patamar de qualidade, a um custo total inferior a uma operação própria. A terceirização passou a ser percebida pelas organizações como necessidade para a concentração em suas atividades principais.

O mercado em formação de operadores logísticos procurava neste momento atender a qualquer segmento, em uma clara tentativa de ganhos de escala e penetração no mercado em um processo similar ao ocorrido no mercado norte-americano. Essa postura, porém passou a ser duramente criticada pelos clientes, pois havia a percepção de que não se poderia fornecer um bom atendimento a todos os segmentos devido às inúmeras peculiaridades e necessidades diferenciadas de cada operação. Surgiu assim, um movimento no mercado preocupado não só com os custos operacionais, mas com a especialização e a flexibilidade de seus futuros parceiros logísticos. Enquanto a especialização levava a um melhor desempenho operacional, a flexibilidade garantia o atendimento as mais diferentes necessidades. A grande massa de clientes passou a cobrar também a integração das diversas soluções informatizadas e maior transparência no setor.

Em 2003, o setor começou a ser visto como promissor e por ser ainda muito recente, apresentava diversas oportunidades para crescimento. Mesmo considerando toda a evolução no Brasil, os maiores operadores eram (e ainda são) considerados apenas médios em relação a mercados como o norte-americano e europeu e mesmo com as dificuldades, entre elas a burocracia e a seleção natural que se espera em um setor hiper-concorrido como esse, novos investimentos estavam sendo esperados.

A tecnologia passou a não ser mais um diferencial competitivo, mas uma necessidade para o segmento. Soluções tecnológicas mais complexas, como sistemas de SCM, tornaram-se investimentos muito elevados e distantes para os pequenos e médios operadores. Para eles, os custos de adaptação destes sistemas até hoje são proibitivos para a realidade do mercado brasileiro.

Ainda em 2003, esperava-se que a fase de contratações de operadores logísticos como solução para reduções de custos fosse enfim substituída por uma postura voltada ao desempenho operacional, como verificado em outros mercados. Não foi o que se observou. A pressão por redução de preços se acentuou, juntamente com a cobrança por um melhor desempenho.

Embora o mercado tenha sentido uma melhora com relação aos serviços prestados, os operadores ainda estavam aquém das necessidades operacionais de seus clientes. As causas apontadas foram a falta de capacidade em investir em equipes técnicas e o desenvolvimento de projetos. Em geral, a equipe de projetos trabalhava apenas até o início da operação e perdia-se a oportunidade de repensar melhorias durante o andamento da operação. 
Pode-se notar, também em 2003, a associação de grandes embarcadores com operadores de porte equivalente (com presença global), como forma de garantir o cumprimento dos contratos. Notou-se nesta época, o surgimento dos indicadores de desempenho atrelados aos contratos de prestação de serviços, porém a recente indústria de operadores carecia de profissionais tecnicamente especializados para executarem as atividades demandadas pela indústria.

A partir de 2004 teve início a demanda por soluções mais sofisticadas e projetos mais complexos, porém uma grande massa de clientes ainda focava a redução de custos operacionais como o principal objetivo para a terceirização da logística.

O setor projetava a redução das margens em seus clientes e obviamente, reduções nas margens cobradas em seu serviço, porém, essa redução poderia provocar a queda da qualidade. Obrigados a constantes reduções em seus custos e forçados a competir em um mercado cada vez mais inflado pelo constante crescimento da oferta, os operadores optaram por soluções operacionais de "segunda categoria", para fazer valer o contrato de prestação de serviços, ao custo exigido pelos clientes. A rentabilidade menor geralmente forçava a um projeto e operação com extensiva utilização de mão-de-obra. Porém alguns operadores começam a enxergar que, para driblar esta pressão por preços, deveriam se posicionar como parceiros estratégicos efetivos, investindo para isso fortemente em informação e interface como o ERP (enterprise resource planning - sistema de planejamento de recursos empresariais) do cliente, porém persistia a dificuldade na obtenção de mão-de-obra, tecnicamente especializada para desenvolver e implantar processos logísticos mais complexos.

Em paralelo as dificuldades impostas pelo mercado, o setor passou a experimentar enormes dificuldades decorrentes do chamado "apagão logístico", caracterizado pela carência de investimentos na infra-estrutura portuária, rodoviária e ferroviária, que elevou os custos operacionais brasileiros em comparação as operações internacionais.

A opinião de especialistas, ainda em 2004, dava como praticamente encerrada a fase de entrada de grandes empresas internacionais e que o momento era de consolidação da situação vista nesta ocasião.

A consolidação da terceirização como ferramenta estratégica e fonte de diferencial competitivo, atingiu momento de maior maturidade entre 2005 e 2006. Nestes últimos anos, acentuou-se a necessidade da organização focar seus esforços e investimentos em seu negócio (core business) e a terceirização foi encarada como fonte de flexibilidade e redução de custos. Consolidou-se nessa época, o conceito de que o sucesso decorre da escolha correta do operador e da formatação do contrato onde se prevê as obrigações de cada parte envolvida. Os embarcadores concordam que parte deles a definição do que se deseja. A falha, eles próprios admitiram, está em muitas vezes não saber o que se quer. 
Em sua maioria, os operadores são ainda contratados para realizar as funções básicas, porém serviços como desembaraço aduaneiro, gerenciamento de transporte intermodal, montagem de kits, milk run, gestão de estoques e desenvolvimento de projetos e soluções, ainda que iniciativas tímidas, começam a ganhar espaço no mercado.

A constatação das dificuldades envolvendo a infraestrutura logística do país, tema levantado em 2004, não foram equacionados e o repasse dos custos, mesmo que em parte, não foram conseguidos pelos operadores.

Os contratos firmados em anos anteriores, durante o período de expansão do mercado de operadores logísticos, começaram a ser quebrados em 2006 e nota-se no mercado brasileiro a formatação de contratos de menor duração (de um a dois anos). Entre as causas apontadas estão: qualidade dos serviços, preços altos, pouca capacitação técnica, fragilidade financeira do operador, problemas éticos, dificuldades de relacionamento e questões de segurança.

Barros (2009) confirma que a principal motivação para a terceirização ainda é a necessidade de cortar custos e a má qualidade dos serviços prestados o principal fator para a substituição de um operador. Atualmente, o setor de logística movimenta R\$ 192 bilhões sendo 63\% deste total destinados aos PSLs.

\section{O Integrador logístico (4PL)}

Para Lima (2004a) e Li et al. (2003) o termo 4PL surgiu devido à demanda do cliente por soluções completas de gerenciamento da cadeia de suprimentos que fornecesse mais valor à cadeia em termos de melhores serviços com entregas pontuais a custos reduzidos, atuando como interface única entre o embarcador (cliente) e várias empresas prestadoras de serviços. Em seu trabalho, Costa (2007, p.84) resume o conceito de 4PL como "um agente integrador e gestor da cadeia de suprimentos que reúne e gerencia recursos, capacidades e tecnologias, em nome da eficiência de seu cliente podendo desenvolver e operar uma rede de PSL, sendo eles de 3PLs".

A consultora Accenture (BADE; MUELLER, 1999 apud SKJOETT-LARSEN, 2000, p. 125) define 4PL como "um elemento integrador da cadeia de suprimentos que agrupa e gerencia recursos, capacidades e tecnologias próprias e de outros prestadores de serviços, para oferecer uma solução ampla da cadeia de suprimentos, combinando as capacidades de consultoria de gestão e da tecnologia de informação com as dos provedores de serviços logísticos terceirizados (3PL)". Christopher (2007) esclarece que o 4PL torna-se o condutor da cadeia de suprimentos e entrega ao cliente uma completa capacidade de gerenciamento de rede, podendo adotar entre outros modelos de negócio, uma joint venture com seu cliente.

O conceito desenvolvido pela Accenture pode ser definido pela figura 2. 
Figura 2: O conceito de 4PL

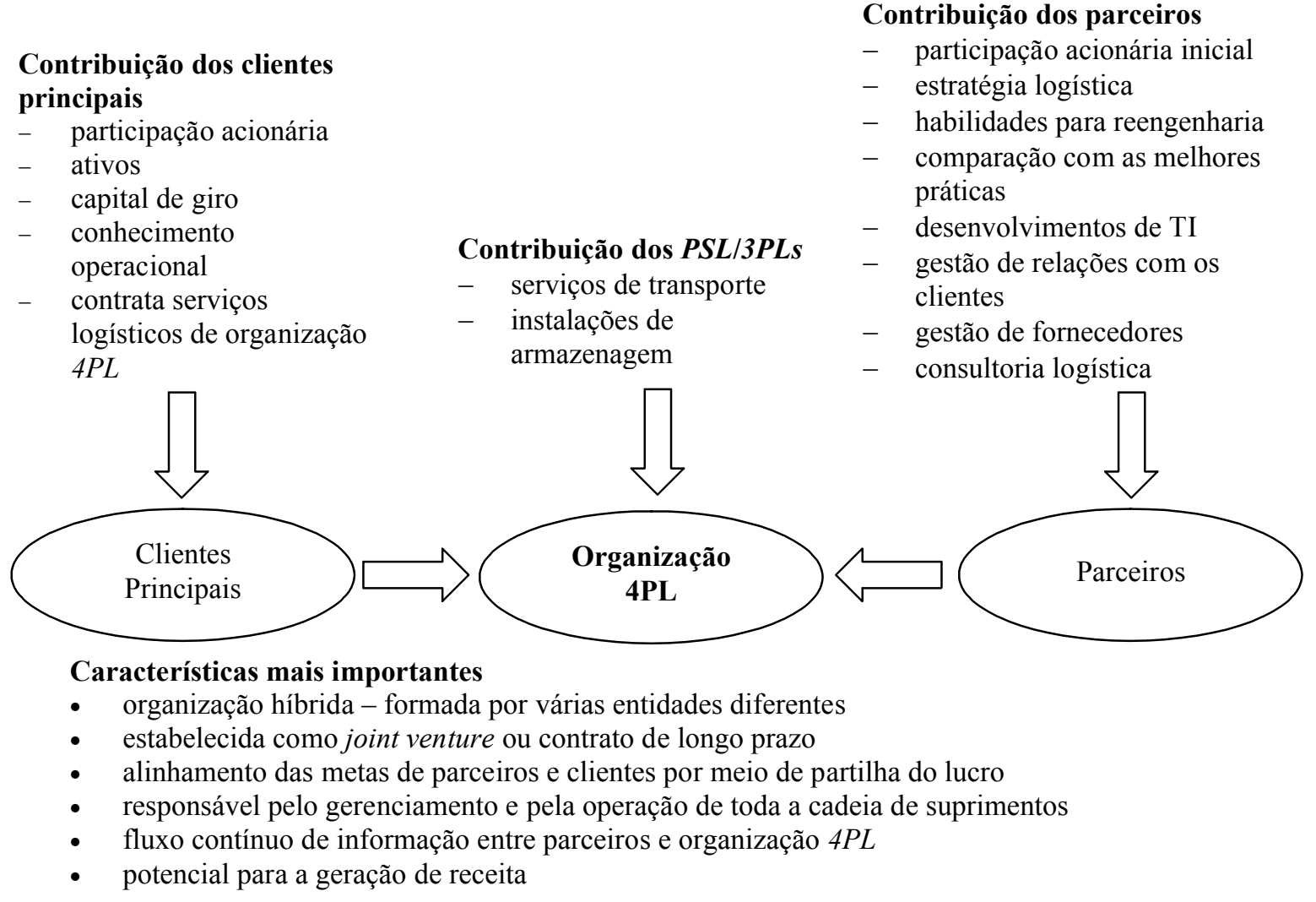

Fonte: Christopher, 2007, p.300

Para Win (2008) os motivos para a contratação de um 4PL incluem um significativo crescimento em volume e/ou mix de produtos, o aumento da demanda por informações relacionadas à cadeia de suprimentos, a necessidade de balancear os estoques com o nível de serviço ao cliente, a mudança do foco do negócio para as atividades de marketing e vendas e baixa acurácia nas previsões de demanda. Entre os atributos do 4PL que devem ser observados no momento de sua seleção destacam-se a experiência em integrar cadeias de suprimentos, seu conhecimento no setor industrial da empresa contratante, a habilidade para executar atividades operacionais de logística e estratégicas relacionadas ao gerenciamento da cadeia de suprimentos, a capacidade de conduzir processos de mudança ou melhoria em áreas como previsão de demanda e S\&OP (sales and operational planning) e a habilidade para gerenciar incertezas de suprimento e demanda.

No Brasil, a parceira entre a Ipiranga Petroquímica (IPQ) e a Companhia Vale do Rio Doce (CVRD) é apontada como o primeiro caso de sucesso de uma relação de nível 4PL, onde a CVRC é responsável pelo desenho da operação logística e pela escolha dos provedores de serviços. Ressaltase, porém que esta iniciativa restringe-se a distribuição dos produtos acabados, embora uma atividade complexa, não se configura em uma ação envolvendo toda a cadeia de suprimentos. $\mathrm{O}$ trabalho de Lima (2004b) destaca a inexistência no Brasil de um integrador logístico, mas ressalta o 
caráter evolutivo deste processo, onde operadores brasileiros estão migrando para o conceito de integrador logístico.

\section{Os processos do Supply Chain Management}

A atuação do operador como integrador logístico no contexto do SCM, o levaria a administrar processos como os definidos por Croxton et al. (2001). Os oito macro-processos descritos pelos autores e por Lambert, Cooper e Pagh (1998) são: (1) A ADMINISTRAÇÃO DO RELACIONAMENTO COM OS CLIENTES diz respeito de como a relação com os clientes é desenvolvida e mantida e como um grupo de clientes pode ser identificado e atingido. (2) A ADMINISTRAÇÃO DO SERVIÇO AO CLIENTE é interface da empresa com seus clientes provendo, por exemplo, informações como datas de embarque de mercadorias e disponibilidade de produtos. (3) A ADMINISTRAÇÃO DA DEMANDA é o processo que lida com o equilíbrio entre as necessidades dos consumidores e a capacidade da empresa em supri-la. (4) A EXECUÇÃO DO PEDIDO requer uma coordenação integrada entre a manufatura, logística e marketing para atender as necessidades dos consumidores. (5) A ADMINISTRAÇÃO DO FLUXO DE PRODUÇÃO lida com a confecção do produto e estabelece a flexibilidade necessária para atingir os mercados-alvo. (6) A ADMINISTRAÇÃO DO RELACIONAMENTO COM FORNECEDORES é o processo que define como a companhia interage com seus fornecedores definindo e gerenciando os indicadores de desempenho. (7) O DESENVOLVIMENTO E COMERCIALIZAÇÃO DE PRODUTOS é um processo vital para a companhia. Sua habilidade em introduzir e comercializar novos produtos, em períodos de tempo cada vez mais reduzidos, determinará em muitas situações a manutenção da competitividade da empresa. (8) A ADMINISTRAÇÃO DA LOGÍSTICA REVERSA lida com o retorno de mercadorias dos clientes para a empresa, tanto em processos pós-venda, como pós-consumo. Estes macro-processos atravessam seis estruturas departamentais básicas, identificadas por Lambert, Cooper e Pagh (1998) como: compras, produção, logística, pesquisa e desenvolvimento, finanças e marketing. A importância de cada um destes processos varia conforme o negócio, sendo cada processo dividido em dois níveis: estratégico e operacional. Cada um deles, constituído de sub-processos que por sua vez possuem interface com os demais macro-processos.

\section{Metodologia}

O estudo conduzido neste trabalho é retrospectivo com base em dados levantados entre 2000 e 2004. Optou-se por uma operação envolvendo uma empresa alinhada com a tendência de formação de redes de relacionamentos empresariais e considerada uma das mais importantes empresas do mercado mundial em seu segmento. A companhia apresentava expressiva participação no mercado brasileiro, produtos reconhecidamente líderes e de destacada qualidade. Para o controle 
logístico de sua operação, o laboratório contava com um operador logístico com grande potencial para o desenvolvimento e utilização de tecnologia da informação.

Duas foram as fontes de coletas de dados utilizadas nessa pesquisa: a observação participante e entrevistas. A oportunidade de realizar a pesquisa com a observação participante possibilitou o acesso aos contratos, comunicações internas, reuniões e discussões de trabalho. Os vieses resultantes da observação participante puderam ser amenizados com os dados coletados nas entrevistas. A escolha dos entrevistados, por sua vez, teve como objetivo atingir diferentes interpretações e pontos de vistas para um confronto com os dados coletados na observação participante, além de reduzir a subjetividade e os vieses também embutido nos entrevistados (VOSS; TSIKRIKTSIS; FROHLICH, 2002).

As entrevistas foram realizadas com mais de um funcionário (dois) de cada organização, em diferentes posições hierárquicas (EISENHARDT; GRAEBNER, 2007), sendo um analista e um exdiretor do laboratório e um ex-supervisor e um gerente operacionais do 3PL. Devido à dificuldade em se obter aprovações para se gravar as entrevistas, optou-se por anotar os depoimentos em blocos de papel e depois transcrevê-los em formato eletrônico utilizando um processador de textos.

Não foram utilizados questionários para se elaborar as entrevistas, mas um guia com os objetivos a serem atingidos. Desse modo, as entrevistas foram conduzidas de modo informal como uma conversa estruturada. Os objetivos foram construídos com base no modelo proposto por Croxton et al. (2001) e Lambert, Cooper e Pagh (1998) para explicar os processos do SCM. Assim, as entrevistas visaram identificar as atividades do 3PL na operação objeto do estudo de caso e relacioná-las com o referido modelo.

Para a análise dos dados, após a reconstrução dos depoimentos em formato de narrativa, compararam-se os principais conceitos discutidos e coletados nas entrevistas (tipo de relacionamento, as funções do 3PL e os processos do $\mathrm{SCM}$ ) com a revisão da literatura. $\mathrm{O}$ entendimento sobre a possibilidade de atuação como 4PL e de sua diferenciação com os outros PSL emergiu deste processo.

\section{Estudo de caso}

A Coopers Brasil era um laboratório farmacêutico localizado em Cotia, município da Grande São Paulo, atuando no mercado de saúde animal. A empresa estava organizada em três unidades de negócio: uma voltada para pecuária (corte e leite), outra dedicada a aves e suínos e a última para animais de companhia. Seus produtos eram reconhecidos e eram marcas de referência no mercado.

A segmentação de clientes definida pela Coopers dividia os clientes em parceiros distribuidores, atacadistas, varejistas, indústrias e grandes propriedades rurais. A empresa definia 
como parceiros distribuidores os grandes atacadistas regionais que tinham exclusividade de atuação comercial sobre determinada região e possuíam algumas vantagens comerciais e logísticas.

Quando a matriz da empresa estabeleceu que todas as atividades industriais da operação brasileira deveriam ser totalmente terceirizadas ficou decidido que as operações logísticas seguiriam as mesmas determinações, mantendo apenas uma pequena operação em um centro de distribuição avançado (CDA) em Curitiba que atendia a grandes empresas na região em especial, no oeste de Santa Catarina. Assim, como na contratação de fornecedores para o processamento dos produtos acabados, houve extremo rigor para a contratação do 3PL encarregado das operações logísticas.

Do total de notas expedidas, 90\% eram entregues dentro dos prazos contratados e a participação dos custos logísticos sobre o faturamento da empresa estava em torno de $6 \%$. As transportadoras contratadas e os funcionários já haviam absorvido as dificuldades da operação, que como na maioria das empresas, possuía uma concentração de vendas na última semana de mais ou menos $70 \%$ do volume mensal. Esta situação, na verdade, contribuía para a queda no desempenho e aumento dos custos. O ponto negativo da operação estava associado aos recursos disponíveis, como por exemplo, a ausência de investimentos em sistemas de informações.

Da mesma forma que os processos logísticos, a fabricação terceirizada impôs a divisão de operações um enorme desafio. Abandonar uma estrutura de produção própria e adotar a terceirização de toda a linha de produtos se constituiu em um desafio gerencial ligado ao processo de mudança cultural e formatação de novas habilidades gerenciais e operacionais, envolvendo a formatação de contratos e negociações buscando a conciliação de exigências tão diferentes como disponibilidade de produto, custo e qualidade.

A Schering-Plough Coopers operava com dois grupos de fornecedores: grandes empresas, em geral multinacionais e concorrentes globais e pequenas e médias empresas nacionais, fabricantes de produtos similares ou mesmo concorrentes. Para qualquer um dos grupos eram dois os formatos de contratos de terceirização oferecidos que se diferenciavam pelo grau de responsabilidade do fornecedor. O contrato batizado de Full Manufacturing transferia ao fornecedor toda a responsabilidade ao fornecedor e o contrato de terceirização onde o fornecedor se encarregava apenas da produção. Em geral as grandes empresas aderiam a esta modalidade. Já as pequenas e médias não conseguiam formatar este tipo de proposta pois, não possuíam a estrutura e mão de obra qualificada para atender a todo o conjunto de exigências e necessidades. Esta operação exigia além das preocupações com a produção, todos os cuidados com o recebimento e armazenagem de matérias-primas e produtos acabados, além de um complexo gerenciamento de fornecedores, alguns deles internacionais. Desta forma, os pequenos e médios fornecedores optavam pela segunda modalidade de contratação, onde eles assumiam apenas a produção do item, sendo o gerenciamento 
dos fornecedores de matérias-primas e materiais de embalagem, por conta da Schering Plough Coopers.

O quadro 1 resume os modelos de contrato.

Quadro 1: Modalidades de contrato

\begin{tabular}{l|c|c}
\multirow{2}{*}{ Processos } & Full Manufacturing & \multicolumn{2}{c}{ Terceirização } \\
\cline { 2 - 3 } & \multicolumn{2}{|c}{ Responsabilidade } \\
\hline $\begin{array}{l}\text { Planejamento de produtos acabados } \\
\text { (quantidades e prazos) }\end{array}$ & Schering Plough Coopers & Schering Plough Coopers \\
\hline $\begin{array}{l}\text { Explosão das necessidades de materiais } \\
\text { (quantidades e prazos) }\end{array}$ & Fornecedor & Schering Plough Coopers \\
\hline $\begin{array}{l}\text { Negociação e compra da matéria-prima } \\
\begin{array}{l}\text { Transporte, recebimento e armazenagem } \\
\text { dos materiais utilizados na produção }\end{array}\end{array}$ & Fornecedor & Schering Plough Coopers \\
\hline
\end{tabular}

A linha de produtos possuía três diferentes exigências de armazenamento, diretamente ligadas à temperatura: carga seca, carga refrigerada e carga congelada. A carga seca devia ser armazenada e transportada em condições consideradas como "temperatura ambiente", mas que de fato não deveriam ultrapassar $25^{\circ} \mathrm{C}$ e eram transportadas em caixas de papelão. As cargas refrigeradas em câmaras frias deveriam permanecer entre $2^{\circ} \mathrm{C} \mathrm{a} 8^{\circ} \mathrm{C}$ e eram expedidas em caixas de isopor com gelo para a conservação da temperatura. As cargas congeladas seguiam em botijões com nitrogênio líquido, conservando as vacinas a $-170^{\circ} \mathrm{C}$. Tanto para as congeladas quanto para as refrigeradas, o tempo máximo de transporte (do depósito até o cliente) era de 48 horas. Após este período a mercadoria era considerada imprópria para uso e invariavelmente seguia para a destruição (incineração).

A contratação de um 3PL visou prioritariamente os processos de armazenagem, gerenciamento de estoques de produtos acabados, separação de pedidos e gerenciamento do transporte, envolvendo a definição dos modais, seleção e contratação de transportadoras e acompanhamento do desempenho operacional. As matérias-primas, materiais de embalagem e materiais promocionais ficaram nas instalações da antiga fábrica, desativada com a terceirização total da operação. A disponibilidade de área de armazenagem e o baixo giro dos produtos justificavam, em uma primeira análise, a exclusão destes itens na negociação com os 3PLs.

Foi necessária a abertura de uma concorrência para identificar um 3PL capaz de receber, armazenar, separar, embalar (se necessário), identificar os volumes e entregar produtos farmacêuticos veterinários (respeitando as características de cada produto) em todo o território brasileiro. Desta maneira, o 3PL ideal deveria se situar dentro do Estado de São Paulo, num raio de até $100 \mathrm{~km}$ da antiga sede da fábrica na Grande São Paulo, apresentar uma área disponível para 
armazenagem com capacidade para aproximadamente 2.000 paletes, $500 \mathrm{~m}^{3}$ de câmaras frigoríficas e área e infra-estrutura disponíveis para o armazenamento e manuseio de produtos armazenados em nitrogênio líquido. Além destas características operacionais, o operador deveria contar com a licença expedida pelo Ministério da Agricultura, Pecuária e Abastecimento (MAPA).

Esperava-se que o 3PL contratado pudesse superar o desempenho operacional de entregas da empresa, garantindo que no mínimo, 95\% das notas fiscais expedidas fossem entregues dentro dos prazos contratados e com a manutenção de custos compatíveis com o mercado de saúde animal. A definição do 3PL não passou pela matriz americana, porém envolveu toda a empresa em um processo que culminou com a contratação da AGV (Armazéns Gerais Vinhedo) Logística.

A AGV Logística possuía 6 anos de experiência no mercado. Sua matriz estava localizada no interior de São Paulo e a empresa contava com outras 17 filiais espalhadas pelo Brasil. Atendia a aproximadamente 50 clientes, divididos em 6 segmentos distintos: alimentos, químicos, logística integrada, logística promocional, saúde humana e saúde animal, onde além da Coopers, ela operava com outros 21 laboratórios. O contrato inicialmente assinado com duração de 2 anos, renovava-se automaticamente no caso de um acordo entre as partes.

A Coopers já era cliente da AGV Logística. Anos antes, a AGV Logística foi escolhida pelo governo federal, como a empresa responsável pela selagem, armazenamento e distribuição de vacinas contra a febre aftosa (carro chefe da empresa) e raiva dos herbívoros.

A AGV foi contratada pela sua infra-estrutura, pela proposta comercial (pois reduziria o custo de logística para a Coopers em $5 \%$ do seu faturamento), larga experiência no segmento veterinário e excelente relacionamento com o MAPA e o Sindicato Nacional da Indústria de Produtos para Saúde Animal (SINDAN). O quadro gerencial da empresa era jovem, com boa formação, conhecia o mercado de saúde animal e era bem relacionado com seus pares da Coopers, entretanto o pessoal operacional se revelava carente de formação e conhecimentos técnicos.

A proposta de trabalho da AGV contemplava o atendimento integral por meio de uma linha completa de serviços, equipe dedicada e o desenvolvimento de áreas com tamanhos e características demandadas para cada operação da Coopers. Entre os serviços disponíveis estavam o transporte e distribuição, armazenagem, recebimento, picking, paletização, expedição, cross-docking, unitização, conferência, embalagem, rotulagem e etiquetagem.

A tecnologia que suportava a operação da AGV Logística também foi avaliada. Era uma estrutura básica que suportava as necessidades imediatas da Coopers, porém a contratação da AGV indicava um potencial nesta área, pois a empresa possuía sua própria softwarehouse, a Alvo Informática. Os sistemas utilizados eram: WMS (Warehouse Management System), sistema de gerenciamento de armazéns com Radio Freqüência e o TMS (Transport Management System), sistema de gerenciamento de transportes. 
No início, as operações se restringiam as funções básicas, relacionadas com a logística do produto acabado, porém rapidamente a $\mathrm{AGV}$ teve que lidar com novos desafios e passou a exercer outras funções. Durante as negociações com a AGV, a Coopers anunciou uma fusão com a Schering-Plough Veterinária. A Coopers Brasil que já atuava como uma subsidiária da ScheringPlough Internacional passou a controlar toda a divisão veterinária da companhia no Brasil. A empresa resultante do processo de fusão passou a se chamar Schering-Plough Cooper e com o crescimento do negócio, a área de armazenagem de carga seca foi alterada para 4.000 paletes e a área refrigerada para $600 \mathrm{~m}^{3}$. A operação da vacina contra febre aftosa não sofreu alterações.

O fluxo operacional iniciava na compra da matéria-prima - entregue pelos próprios fornecedores na antiga fábrica da Coopers ou em algumas situações, nas instalações dos fornecedores. Após a fabricação dos produtos, a retirada no fornecedor era direcionada a AGV que enviava o lote produzido para suas instalações no interior de São Paulo. As quantidades recebidas alimentavam o WMS da AGV Logística e por meio de um arquivo eletrônico, alimentavam o sistema da Schering-Plough Coopers. O processo de faturamento era feito pela Schering-Plough Coopers mas a impressão da nota físcal ocorria na AGV Logística. A partir deste ponto ela era responsável pela separação, conferência, embalagem e transporte do pedido até o destinatário. Mesmo com toda a movimentação, o WMS da AGV garantia uma acurácia dos números em estoque de quase $100 \%$. O TMS da empresa garantia todo o acompanhamento do pedido até a efetivação da entrega.

A relação entre as empresa evoluiu e novas atividades foram desenvolvidas em conjunto. Após 6 meses da terceirização completa de suas operações, a Schering-Plough Coopers iniciou a importação de produtos semi-acabados para a finalização do processo no Brasil com a colocação dos rótulos, embalagem, impressões na embalagem e embalagem de embarque (caixa de papelão para transporte). A AGV Logística selecionou o pessoal e disponibilizou uma área especifica para o trabalho de rotulagem, impressão de cartuchos e embalagem, anexa ao depósito. A premissa inicial de importar os produtos enviá-los a um dos fornecedores de produtos acabados e depois despachálos para a AGV foi abandonada com a introdução desta operação, com visíveis ganhos no custo e proporcionando agilidade e disponibilidade imediata dos produtos para venda. A figura 3 resume a operação: 
Figura 3: Resumo da operação logística

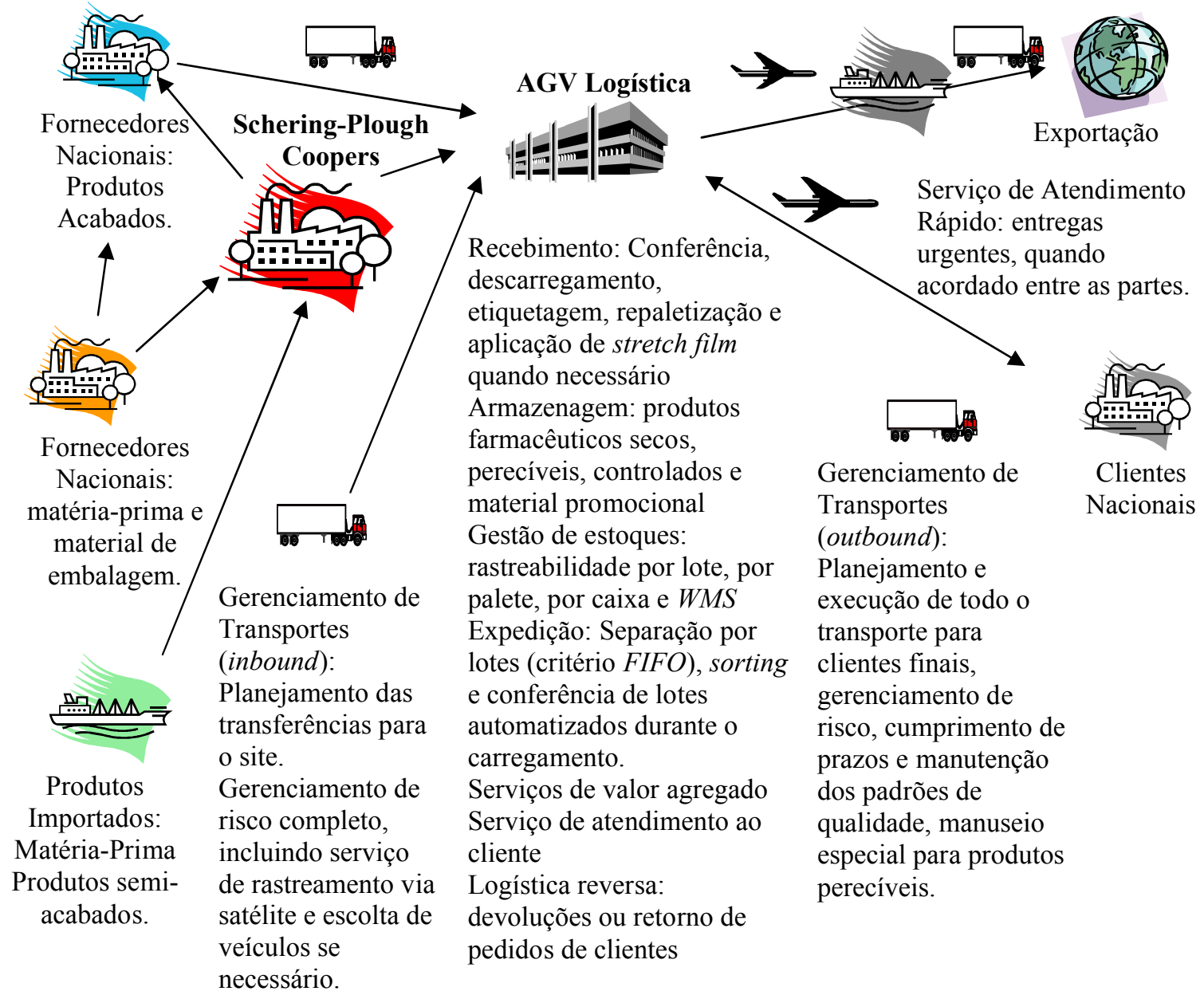

Atividades de consultoria também foram prestadas pela AGV nas regiões com baixo percentual de entregas no prazo. Para analisar este problema, uma vez que as substituições de transportadoras e os planos de melhorias junto às empresas destas regiões não surtiram o efeito desejado, a AGV Logística despachou seu gerente de transporte para uma viagem por estas regiões. Esse trabalhou gerou um dossiê com fotos e relatos de vendedores e clientes sobre as dificuldades e peculiaridades das regiões, buscando entender profundamente a operação de distribuição em cada um dos Estados que apresentavam queixas de atrasos. Constatou-se que a concorrência operava com CDAs nestas regiões com maior dificuldade, oferecendo, portanto um tempo de resposta mais curto (entre o pedido e a entrega) que o oferecido pela Schering-Plough Coopers. Iniciou-se um projeto conjunto entre as duas empresas, onde a AGV Logística se prontificou a operar a partir de suas instalações em Cuiabá, Goiânia e uma terceira a ser aberta em Recife com área exclusiva para a Schering-Plough Coopers. Em troca, para financiar os investimentos do projeto, a Schering-Plough Coopers passaria a gestão do seu CD em Curitiba para a AGV Logística. Havia o interesse em 
aumentar a participação deste CD nas operações. Embora considerado estratégico devido a seu posicionamento, mas com a necessidade de investimentos em um novo local, equipamentos e pessoal (o $\mathrm{CD}$ era muito pequeno e operava apenas com dois funcionários), o projeto para incrementar o movimento desta filial nunca foi levado adiante. Entretanto, a terceirização deste CD contribuiu para a realização deste projeto. Para minimizar os custos de estoques, mesmo considerando reduções nos custos com transportes, apenas parte dos produtos (aqueles considerados principais) seriam transferidos para os CDs, respeitando as classes terapêuticas e os produtos destinados aos principais rebanhos de cada região. Estimou-se um aumento nos custos logísticos totais de apenas $0,3 \%$ sobre o faturamento, o que seria superado pelo aumento na participação de mercado via melhor atendimento aos clientes.

Com as operações cada vez mais consolidadas, o próximo passo foi o alinhamento do fluxo de informações. Para isso, no acompanhamento das entregas a AGV montou um time de atendentes que tinham como função telefonar para os destinatários e colher informações sobre o atendimento prestado pelas transportadoras, estado da mercadoria, etc. Esta sistemática visava o aperfeiçoamento do trabalho da AGV no gerenciamento das transportadoras, porém as oportunidades oriundas desta iniciativa, motivaram o desenvolvimento de projetos para a utilização destas informações pela Schering-Plough Coopers em ações de CRM (customer relationship management) que poderiam ser planejadas e implementadas em conjunto.

\section{Discussão}

Como um 3PL poderia se diferenciar entre os PSLs a ponto de ser considerado um 4PL? A projeção oferecida pelo estudo de caso e pela literatura sugere uma resposta a esta questão, objetivo proposto neste trabalho.

Com base nos oito macro-processos definidos por Croxton et al. (2001) e Lambert, Cooper e Pagh (1998) para o SCM pode-se visualizar um quadro teórico sobre as possibilidades de atuação de um 4PL:

(1) e (2) RELACIONAMENTO E SERVIÇO AO CLIENTE: a AGV estava em contato direto e permanente com os clientes da Schering-Plough Coopers. Este contato possibilitaria ações envolvendo:

a) segmentação de clientes com a oferta de níveis de serviço específicos e diferenciados e a criação de times gerenciais responsáveis por contas especiais;

b) identificação de oportunidades de mercado auxiliando a equipe de vendas na captação de novas contas;

c) implementar ações de vendor managed inventory (VMI);

d) contribuir com trabalhos de consultoria, no desenho de soluções logísticas para os 
clientes da Schering-Plough Coopers, como os parceiros distribuidores. Neste caso, auxiliando-os por exemplo, na distribuição, armazenamento e no atendimento a pequenos varejistas.

(3) e (5) ADMINISTRAÇÃO DA DEMANDA E DA PRODUÇÃO: a AGV contribuiria com o planejamento dos estoques, por meio da coleta de informações de clientes e do mercado com a posterior análise dos dados com o auxilio de ferramentas especificas de forecast. Criariam-se as bases para o incremento da flexibilidade da produção e variações de estoques, bem como, para o planejamento dos recursos alocados na operação logística.

(4) EXECUÇÃO DO PEDIDO: é a essência do trabalho operacional da AGV é por isso amplamente atendido pela AGV.

(6) ADMINISTRAÇÃO DO RELACIONAMENTO COM FORNECEDORES: este é um processo crítico em uma operação como a da Schering-Plough Coopers, totalmente terceirizada. A contratação de pequenos fornecedores propicia soluções mais ágeis, porém adiciona complicações logísticas que dificilmente estes pequenos parceiros conseguem solucionar. A AGV poderia desenvolver, implantar e controlar projetos e soluções logísticas a estes pequenos fornecedores com ganhos para todos os envolvidos. Rotinas para avaliação de fornecedores podem ser também implantadas pela AGV.

(7) DESENVOLVIMENTO E COMERCIALIZAÇÃO DE PRODUTOS: uma fonte de prejuízos e retrabalhos em logística é a falta de uma perfeita sincronia entre as funcionalidades do produto e suas características de armazenamento e transporte. Seria importante envolver a AGV durante o projeto de produto, especificamente no desenvolvimento de embalagens. A AGV também realizaria estudos que auxiliariam na definição dos canais de distribuição para novos produtos.

(8) ADMINISTRAÇÃO DA LOGÍSTICA REVERSA: a AGV poderia oferecer pronta solução aos casos de retornos e devoluções e instituir programas para minimizá-las. Além deste aspecto, questões envolvendo o meio ambiente irão cada vez mais preocupar as empresas e os operadores serão cada vez mais requisitados para se envolver e prover soluções a estas operações.

Uma operação com base nos oito processos do SCM exigiria do 3PL capacidade de gerenciamento em uma operação com alto grau de complexidade. Recursos como sistemas, equipamentos, áreas de armazenagem e mão de obra especializada deveriam ser empregadas em uma operação como a descrita, sugerindo a especificidade na utilização desses recursos. $O$ cruzamento da complexidade e especificidade resultantes deste novo cenário, indicam um modelo de relacionamento similar a organização em rede proposta por Franceschini et al. (2003). Neste contexto, o termo "integrador" aplicado como evolução do termo "operador", avaliza o conceito de um provedor capaz de integrar processos entre organizações em uma cadeia de suprimentos. $\mathrm{O}$ termo "logístico" atribuído a ambos não seria, porém o mais apropriado, pois os processos logísticos são apenas parte de um conceito mais abrangente compreendido como SCM (COOPER; 
LAMBERT; PAGH, 1997). A ampliação de sua atuação para um contexto cobrindo o gerenciamento de processos em toda a cadeia de suprimentos (LAMBERT; COOPER; PAGH, 1998) exigiria termos como "integrador de cadeias de suprimentos" ou "integrador de rede", entretanto, o conceito integrador logístico ou fourth-party logistics é reconhecidamente aceito e em corrente uso pelo mercado.

A partir dessa discussão pode-se completar o quadro comparativo proposto por Razzaque e Sheng (1999) entre agentes que constituem a indústria de PSLs incluindo as características identificadas para o 4PL (quadro 2).

Quadro 2: Comparação das características dos provedores de serviços logísticos.

\begin{tabular}{|c|c|c|}
\hline $\begin{array}{c}\text { Prestador de Serviços Tradicionais } \\
\text { (PSL) }\end{array}$ & $\begin{array}{l}\text { Operador Logístico } \\
\text { (3PL) }\end{array}$ & $\begin{array}{l}\text { Integrador Logístico } \\
\text { (4PL) }\end{array}$ \\
\hline $\begin{array}{l}\text { Oferece serviços genéricos - } \\
\text { commodities. }\end{array}$ & $\begin{array}{l}\text { Oferece serviços sob medida - } \\
\text { personalizados. }\end{array}$ & $\begin{array}{l}\text { Oferece soluções integradas e } \\
\text { específicas para o segmento de } \\
\text { negócio de seus clientes. }\end{array}$ \\
\hline $\begin{array}{l}\text { Tende a se concentrar numa única } \\
\text { atividade logística; transporte ou } \\
\text { estoque, ou armazenagem, por } \\
\text { exemplo. }\end{array}$ & $\begin{array}{l}\text { Oferece múltiplas atividades de forma } \\
\text { integrada; transporte, estoque e } \\
\text { armazenagem. }\end{array}$ & $\begin{array}{l}\text { Desenvolve múltiplos processos ao } \\
\text { longo da cadeia de suprimentos de } \\
\text { seus clientes. }\end{array}$ \\
\hline $\begin{array}{l}\text { O objetivo da empresa contratante do } \\
\text { serviço é minimização do custo } \\
\text { específico da atividade contratada. }\end{array}$ & $\begin{array}{l}\text { Objetivo da contratante é reduzir os } \\
\text { custos totais da logística, melhorar os } \\
\text { serviços e aumentar a flexibilidade. }\end{array}$ & $\begin{array}{l}\text { O objetivo da contratante é reduzir os } \\
\text { custos totais de sua cadeia de } \\
\text { suprimentos e desenvolver vantagens } \\
\text { competitivas com a entrega de valor } \\
\text { superior aos consumidores finais. }\end{array}$ \\
\hline $\begin{array}{l}\text { Contratos de serviços tendem a ser de } \\
\text { curto a médio prazo ( } 6 \text { meses a } 1 \\
\text { ano). }\end{array}$ & $\begin{array}{l}\text { Contratos de serviços tendem a ser de } \\
\text { longo prazo ( } 2 \text { a } 5 \text { anos). }\end{array}$ & $\begin{array}{l}\text { Joint ventures ou contratos de } \\
\text { serviços tendem a ser de longo prazo } \\
\text { (superior a } 5 \text { anos). }\end{array}$ \\
\hline $\begin{array}{l}\text { Know-how tende a ser limitado e } \\
\text { especializado (transporte, } \\
\text { armazenagem, etc.). }\end{array}$ & $\begin{array}{l}\text { Possui ampla capacitação de análise e } \\
\text { planejamento logístico, assim como } \\
\text { de operação. }\end{array}$ & $\begin{array}{l}\text { Possui elevada capacidade de } \\
\text { planejamento estratégico e } \\
\text { operacional apoiado com grande } \\
\text { infra-estrutura tecnológica. }\end{array}$ \\
\hline $\begin{array}{l}\text { Negociações para os contratos tendem } \\
\text { a ser rápidas (semanas) e num nível } \\
\text { operacional. }\end{array}$ & $\begin{array}{l}\text { Negociações para contrato tendem a } \\
\text { ser longas (meses) e num nível de alta } \\
\text { gerência. }\end{array}$ & $\begin{array}{l}\text { Negociações conduzidas pela alta } \\
\text { direção e de longa duração. }\end{array}$ \\
\hline $\begin{array}{l}\text { Acordos mais simples e custo de } \\
\text { mudança relativamente mais baixo. }\end{array}$ & $\begin{array}{l}\text { A complexidade dos acordos leva a } \\
\text { custos de mudança mais altos. }\end{array}$ & $\begin{array}{l}\text { A interdependência dos parceiros de } \\
\text { negócio tende a elevar os custos de } \\
\text { mudança não só em termos } \\
\text { financeiros, mas com impacto na } \\
\text { cultura empresarial também. }\end{array}$ \\
\hline
\end{tabular}

Fonte: Adaptado de Razzaque e Sheng, 1999 


\section{Considerações Finais}

Este artigo sugere que as operações resultantes desse novo modelo de integração logística, cobrindo os oito processos do SCM, diferenciariam os 3PL da disputada hoje centrada em preço e eficiência operacional, para um foco mais direcionado a inteligência logística.

Especula-se que a maturidade em que se encontra a indústria de operadores logísticos no Brasil possibilitaria a criação de um novo tipo de organização, porém limitações impostas pelo próprio operador e pela empresa contratante não permitiriam o 3PL assumir a operação como um 4PL nos moldes aqui propostos. Por parte do 3PL observam-se limitações envolvendo principalmente a atual base tecnológica (alicerçada em softwares operacionais e não analíticos) e a capacitação técnica de sua mão-de-obra operacional que precisaria ser desenvolvida para prover soluções mais amplas na cadeia de suprimentos. Somente uma ampla solução para estes dois pontos é que permitiria aos 3PLs desenvolver funções mais abrangentes. Já a empresa contratante poderia restringir o papel do 3PL pela percepção que seria estratégico manter o comando operacional de alguns processos.

Duas linhas de estudo poderiam ser conduzidas partir deste trabalho. Inicialmente futuras pesquisas poderiam investigar profundamente as competências que deveriam ser construídas por um 3PL para assumirem responsabilidades de integração de processos na cadeia de suprimentos. Outra linha de pesquisa poderia ser conduzida a partir do entendimento da emergente dificuldade imposta às cadeias de suprimentos, resultante das questões envolvendo a sustentabilidade e a responsabilidade social. Os desafios socioambientais irão exigir habilidades que extrapolam as funções logísticas de competência dos 3PL, que desta forma, serão desafiados a prover soluções em um ambiente onde à habilidade em gerenciar operações de suprimento, produção e distribuição envolvendo a gestão sustentável de recursos e a relação social com parceiros e comunidade será determinante para a continuidade dos negócios. Provavelmente, habilidades envolvendo o projeto e execução de operações ao longo da cadeia, considerando estes novos desafios, serão atributos altamente demandados, onde se estima que os 4PLs estarão aptos a oferecer soluções.

Cada vez mais se observa a disposição das empresas em se concentrar em suas competências e atividades principais, além de estabelecerem redes de cooperação com entidades externas (fornecedores e clientes). Nesse contexto, atividades de colaboração e coordenação assumem grande importância, gerando desafios gerenciais de grande complexidade que tendem a demandar as competências dos integradores logísticos.

O entendimento teórico de oportunidades de negócio e diferenciação para os operadores logísticos é a principal limitação deste artigo. Não foram avaliadas as condições políticas, institucionais e de mercado com relação à aplicabilidade das operações propostas. Identificou-se 
apenas uma lacuna entre a atuação dos operadores e às mudanças impostas à área de logística no novo cenário competitivo onde eles atuam.

Entre as contribuições praticas deste estudo, espera-se que ele contribua para o debate sobre os operadores logísticos, sua evolução como integradores logísticos e a potencial utilização destes conceitos dentro das cadeias de suprimentos desenhadas em virtude das estratégias empresariais.

\begin{abstract}
The management complexity resulting from the flow of materials and information among enterprise networks has raised the idea of a processes integrator agent acting in these networks. For this new role it is speculated that these new agents should incorporate activities in the supply chain as it raises the level of relationship with the contractor. This research aims to provide opportunities for a third-party logistics highly integrated with their client in the manner described as the "network organization" and differentiate it from other agents who operate in the outsourcing industry in logistical operations. At this stage the third-party logistics would be characterized as a fourth-party logistics. The survey crossed empirical evidence collected in a case study with eight supply chain management process identified in the literature. The construction of the case study comprised participant observation, interviews with employees and former employees of the companies involved and the data collected from secondary sources. It was identified that the third-party logistics could differentiate itself from other logistics service providers through the provision of integrated solutions for specific customer business segment developing multiple processes along the supply chain. The third-party logistcs must have high capacity for strategic and operational plans supported with great technological infrastructure to assume this new role.
\end{abstract}

Key-words: third-party logistics; fourth-party logistics; supply chain.

\title{
Referências
}

BARROS, M. Terceirização logística no Brasil. Tecnologística, São Paulo, n. 163, p. 118-125, junho, 2009.

BERGLUND, M. et al. Third-party logistics: is there a future? International Journal of Logistics Management, v.10, n 1, p. 59-70, 1999.

cross ${ }^{\text {ref }}$

CHRISTOPHER, M. Logística e gerenciamento da cadeia de suprimentos: criando redes que agregam valor. 2 . ed. São Paulo: Thomson Learning, 2007.

COOPER, M. C.; LAMBERT, D. M.; PAGH, J. D. Supply chain management: more than a new name for logistics. International Journal of Logistics Management, v. 8, n.1, p.1-14, 1997.

cross ${ }^{\text {ref }}$

COSTA, R. B. F. Considerações sobre a terceirização da logística e uma metodologia de classificação para os Party Logistics. Rio de Janeiro, 2007. Dissertação (Mestrado em Engenharia Industrial) - Departamento de Engenharia Industrial, Pontifícia Universidade Católica do Rio de Janeiro.

CROXTON, K.; GARCÍA-DASTUGUE, S. J.; LAMBERT, D. M. The supply chain management process. International Journal of Logistics Management, v. 12, n.2, p.13-36, 2001.

DORNIER, Philippe-Pierre et al. Logística e operações globais: textos e casos. São Paulo: Atlas, 2000.

EISENHARDT, K. M.; GRAEBNER, M. E.. Theory building from cases: opportunities and challenges. Academy of Management Journal, v. 50, n. 1, p.25-32, 2007.

cross ${ }^{\text {ref }}$ 
FAWCETT, S. E.; MAGNAN, G. M. The rhetoric and reality of supply chain integation. International Journal of Physical Distribution \& Logistics Management, v. 35, n. 5, p. 339-361, 2002.

FLEURY, P. F. Vantagens competitivas e estratégias no uso de operadores logísticos (1999). Disponível em: $<$ http://www.cel.coppead.ufrj.br/fr-op-logist.htm>. Acesso em 24 jun. 2002.

FLEURY, P. F.; RIBEIRO, A. F. M. A indústria de prestadores de serviços logísticos no Brasil: Uma análise dos principais operadores (2001a). Disponível em: <http://www.cel.coppead.ufrj.br/fr-ind.htm>. Acesso em: 20 out. 2005.

FLEURY, P. F.; RIBEIRO, A. F. M. A indústria de prestadores de serviços logísticos no Brasil: caracterizando os principais operadores (2001b). Disponível em: <http://www.cel.coppead.ufrj.br/fr-ind.htm>. Acesso em: 20 out. 2005.

FRANCESCHINI, F. et al. Outsourcing: guidelines for a structured approach. Benchmarking: An International Journal, v.10, n.3, p. 246-260, 2003.

LAMBERT, D. M.; COOPER, M. C.; PAGH, J. D. Supply chain management: implementation issues and research opportunities. International Journal of Logistics Management, v. 9, n. 2, p.1-19, 1998.

cross ${ }^{\text {ref }}$

LI, X. et al. The design and realization of four party logistics. IEEE International Conference on Systems, Man and Cybernetics, v. 1, n. 5-8, p. 838-842, 2003.

LIMA, L. R. R. A evolução dos prestadores de serviços logísticos no Brasil: o surgimento dos 4PLs. 2004a. 139f. Dissertação (Mestrado em Engenharia de Produção) - Programa de Pós-Graduação em Engenharia de Produção, Universidade Federal de Santa Catarina, Florianópolis.

LIMA, R. R. de S. Estágio atual e tendências de evolução e atuação dos operadores logísticos como integradores logísticos. 2004b. 181f. Dissertação (Mestrado em Administração) - Programa de Pós-Graduação em Administração, Instituto Coppead de Administração, Universidade Federal do Rio de Janeiro, Rio de Janeiro.

Mercado Brasileiro de Operadores Logísticos. Tecnologística, São Paulo, n.67, p.42-60, junho, 2001.

Mercado Brasileiro de Operadores Logísticos. Tecnologística, São Paulo, n.79, p.56-102, junho, 2002.

Mercado Brasileiro de Operadores Logísticos. Tecnologística, São Paulo, n.91, p.58-112, junho, 2003.

Mercado Brasileiro de Operadores Logísticos. Tecnologística, São Paulo, n.103, p.69-126, junho, 2004.

Mercado Brasileiro de Operadores Logísticos. Tecnologística, São Paulo, n.115, p.86-136, junho, 2005.

MURPHY, P. R; POIST, R. F. Third-party logistics: some user versus provider perspectives. Journal of Business Logistics, v.21, n.1, p.121-133, 2000.

NOVAES, A. G. Logística e gerenciamento da cadeia de distribuição: estratégia, operação e avaliação. Rio de Janeiro: Campus, 2001.

RAZZAQUE, M. Ab.; SHENG, Ch. Ch. Outsourcing of logistics functions: a literature survey. International Journal of Physical Distribution \& Logistics Management, v. 28, n. 2, p. 89-107, 1998.

cross ${ }^{\text {ref }}$

SELVIARIDIS, K.; SPRING, M. Third party logistics: a literature review and research agenda. International Journal of Logistics Management, v. 18, n. 1, p.125-150, 2007.

crossef

SINK, H. L.; LANGLEY, C. J. A managerial framework for the acquisition of third-party logistics services. Journal of Business Logistics, v.18 n.2, p.163-189, 1997.

SKJOETT-LARSEN, T. Third-party logistics - from an organizational point of view. International Journal of Physical Distribution \& Logistics Management, v. 30, n. 2, p. 112-127, 2000.

cross ref 
VIVALDINI, M.; PIRES, S. R. I.; SOUZA, F. B. Agente integrador em cadeias de suprimentos - um estudo teórico sobre Prestador de Serviços Logísticos (PSL). In: XV Simpósio de Engenharia de Produção - SIMPEP, 2008 , Bauru. Anais... Bauru: SIMPEP, 2008.

VOSS, Ch.; TSIKRITSIS, N.; FROHLICH, M. Case Research in Operations Management. International Journal of Operations \& Production Management, v. 22, n.2, p.195-219, 2002.

WIN, A. The value a 4PL provider can contribute to an organization. International Journal of Physical Distribution \& Logistics Management, v. 38, n. 9, p. 674-684, 2008.

crossef

YAO, J. Operational Framework and Decision Flow Analyses on Supply Chain Resources Integration in 4PL. IEEE International Conference on Service Operations, Logistics and Informatics, IEEE/SOLI 2008, v. 2, p. 2135-2140, out. 2008

YIN, R. K. Estudo de Caso: planejamento e métodos. 3.ed. Porto Alegre: Bookman, 2005.

\section{Dados completos do autor:}

Nome completo: Wilian Gatti Junior

Filiação institucional: Universidade de São Paulo (USP)

Departamento: Faculdade de Economia e Administração (FEA)

Função ou cargo ocupado: Doutorando

Endereço completo para correspondência: Rua José Justino Pereira, 323. Bairro: Mandaqui. Cidade:

São Paulo - SP. Brasil. CEP: 02407-140

Telefones para contato: (11) 9102.2731 - (11) 2973-6413

e-mail:wgatti@usp.br

Enviado em: $30 / 06 / 2010$

Aprovado em: 25/06/2011 